\title{
Chitin as a source of energy for rumen ciliates
}

\author{
R. Miltko'1, B. Kowalik, T. Michałowski and G. Bełżecki \\ The Kielanowski Institute of Animal Physiology and Nutrition, Polish Academy of Sciences, 05-110 Jabłonna, Poland
}

KEY WORDS: rumen protozoa, chitin, degradation, fermentation, VFA

Received: $\quad 21$ April 2015

Revised: $\quad 3$ July 2015

Accepted: 9 September 2015

${ }^{1}$ Corresponding author:

e-mail: r.miltko@ifzz.pl

\begin{abstract}
The objective of the present study was to examine and compare the ability of Diploplastron affine and Entodinium caudatum to digest and ferment chitin. Cultivation studies showed that enrichment of the growth medium with this polysaccharide increased the ciliate count $(P<0.05)$. After $2 \mathrm{~h}$ of incubation of ciliates with chitin, a statistically significant increase in the percentage of individuals containing chitin particles was observed $(P<0.05)$, followed by a continuous decrease $(P<0.05)$ in this percentage. Enzymatic studies confirmed the ability of the examined protozoa to digest chitin. The chitinolytic activity of Diploplastron affine was 3.9 and that of Entodinium caudatum was $5.9 \mu \mathrm{mol} \mathrm{N}$-acetyl glucosamine/mg protein/h. The production rates of volatile fatty acids from fermented chitin were 3.9 and $0.5 \mathrm{pmol} / \mathrm{ciliate}$ cell/h for Diploplastron affine and Entodinium caudatum, respectively.
\end{abstract}

\section{Introduction}

The biocenosis of the rumen ecosystem is composed of anaerobic microorganisms. Bacteria are the most abundant at $10^{11}$, followed by ciliates up to $10^{6}$, and fungi at $10^{3}-10^{5}$ per millilitre of rumen fluid (Doré and Mackie, 1997). The most common interaction between protozoa and the other groups is predation (Lee et al., 2001). However, comprehensive studies of the relationship between protozoa and fungi are limited to only a few publications (Morgavi et al., 1993, 1994a,b; Miltko et al., 2014). The predation of fungi by protozoa is a two-step process during which zoospores are engulfed and digested by ciliates. Digestion begins with the degradation of chitin, an important carbohydrate component of the fungal cell wall (Miltko et al., 2014). Chitin is composed of acetyl glucosamine residues linked by $\beta-1,4$-glucosidic bonds. This compound is structurally very similar to cellulose. In contrast to cellulose, however, information about how chitin is degraded and the potential of this carbohydrate as an energy source for protozoa is restricted to
Eudiplodinium maggii (Miltko et al., 2010a,b, 2012) and Diploplastron affine (Bełżecki et al., 2008).

Taking the above into account we undertook the studies reported here. The main goal was to examine and compare the process of digesting chitin by rumen ciliates that exhibit different nutritional preferences: the amylolytic Entodinium caudatum (Abou Akkada and Howard, 1960) and the fibrolytic Diploplastron affine (Michałowski et al., 1986).

\section{Material and methods}

\section{The isolation of rumen ciliates and maintenance of stock cultures}

Protozoa were isolated from the rumen of fistulated sheep. The ciliates Diploplastron (also known as Metadinium affine) and Entodinium caudatum were identified according to Dogiel (1927). Cultivation was initiated by picking 20-30 individuals with features typical of the selected species and inoculating them into separate Erlenmeyer flasks $(50 \mathrm{ml})$ containing $40 \mathrm{ml}$ of two-week-old cultures 
of ruminal bacteria growing on 'caudatum' salt solution (Coleman et al., 1972). The initial cultures of $D$. affine were fed $15 \mathrm{mg}$ of food consisting of: powdered meadow hay $(60 \%)$, wheat gluten $(16 \%)$ and microcrystalline cellulose (24\%), whereas in the diet for E. caudatum, microcrystalline cellulose was replaced by barley flour. Wheat gluten (G5004) and microcrystalline cellulose (310697) were supplied by Sigma-Aldrich (St. Louis, MO, USA). The protozoa were maintained according to the method of Michałowski et al. (1986). Some of the developed cultures were used to inoculate the in vitro experiments. The remaining cultures were separately transferred into the rumen of defaunated sheep (Michałowski et al., 1999). They were multiplied there and used to perform the enzymatic and fermentation experiments.

\section{Effect of chitin on ciliate growth in vitro}

Ciliates were cultivated in a culture medium consisting of 'caudatum' solution (see above) and food. The food of the control cultures was the same as initial cultures and was composed of powdered meadow hay, wheat gluten and barley flour (E. caudatum) or the first two components and microcrystalline cellulose (D. affine). The particular ingredients were supplied in a proportion of: $0.3,0.08$ and $0.06 \mathrm{mg}$ - $\mathrm{ml}^{-1}$ culture per day, respectively. The same food was supplemented with different doses of chitin (C7170, Sigma-Aldrich, St. Louis, MO, USA) at a rate of $0.015,0.03,0.06$ and $0.12 \mathrm{mg} \cdot \mathrm{ml}^{-1}$ culture per day (experimental cultures). The examined protozoa belong to the family Ophryoscolecidae, which prefer solid food particles. The meadow hay and chitin were ground in a high-speed electric grinder. The smallest particles adhering to the lid of the grinder were collected and sieved through a filter of $10 \mu \mathrm{m}$ pore diameter. Three experimental and three control cultures were simultaneously initiated and cultivated for 28 days according to Michałowski et al. (1986). Briefly, the cultures were fed every day, and every fourth day they were transferred to a fresh medium. A new set of flasks was filled with $20 \mathrm{ml}$ of fresh 'caudatum' solution. Each of the maintained cultures was thoroughly mixed and $20 \mathrm{ml}$-portions were quickly transferred into flasks containing fresh medium. Finally, each culture was fed, saturated with $\mathrm{CO}_{2}$ and incubated at $40^{\circ} \mathrm{C}$. On the transfer days samples were collected for counting of the protozoa and preserved with $4 \%$ formaldehyde.

\section{Chitin ingestion and digestion}

The experiment was initiated after 24-h starvation of the 6 replications of ciliates growing on a control diet (see above). After starvation, three of them were incubated without chitin (control cultures), whereas the remaining three (experimental cultures) were fed powdered chitin $\left(0.6 \mathrm{mg} \cdot \mathrm{ml}^{-1}\right)$. All cultures were incubated for $24 \mathrm{~h}$ and sampled to estimate the proportion of individuals filled with chitin. The sampling was performed just before the start of incubation as well as 2, 4, 8, 12, 18 and $24 \mathrm{~h}$ thereafter.

\section{Measurement of chitinolytic activity}

Ciliates cultivated in the rumen of monofaunated sheep were isolated, separated, purified and incubated with chloramphenicol, streptomycin and ampicillin. The final concentration of each of the antibiotics was $50 \mu \mathrm{g} \cdot \mathrm{ml}^{-1}$ (Miltko et al., 2010a). The purified protozoa were collected, lyophilized and stored at $-80^{\circ} \mathrm{C}$. On the day of the experiments, the samples of protozoa were thawed and homogenized. The obtained homogenate was centrifuged at $22000 \mathrm{~g}$ for $30 \mathrm{~min}$ at $4^{\circ} \mathrm{C}$ and the supernatant was collected and used as a crude enzyme preparation.

Chitinolytic activity was determined by the quantification of reducing sugars released during the incubation of the crude enzyme preparation with substrate. Chitin resembles cellulose in that it is an insoluble carbohydrate, thus to obtain a soluble form and homogenous suspension of the substance, chitin was modified to a colloidal form and used in enzymatic studies. Colloidal chitin was prepared according to Shimahara and Takiguchi (1988). The reaction mixture consisted of $0.4 \mathrm{ml}$ of a $0.2 \%$ colloidal chitin solution, $0.4 \mathrm{ml}$ of enzyme preparation and $0.2 \mathrm{ml}$ of $0.1 \mathrm{~mol} \cdot 1^{-1}$ citric-phosphate buffer ( $\mathrm{pH}$ 6.0). The mixture was incubated for $1 \mathrm{~h}$ at $40^{\circ} \mathrm{C}$ and the reducing sugars were measured according to Miller et al. (1960). The enzyme preparation without substrate and the substrate without the enzyme preparation were always concomitantly incubated as controls. The optimal conditions for chitin digestion were estimated by the measurement of the degradation rate of the substrate at $\mathrm{pH}$ and temperature ranges of 3.0 to 8.0 and $30^{\circ} \mathrm{C}$ to $60^{\circ} \mathrm{C}$, respectively. The measurements were repeated three times using three different crude enzyme preparations. The protein content in the crude enzyme preparation was measured with the use of a Microprotein-PR kit (611A SigmaAldrich, St. Louis, MO, USA) according to Fujita et al. (1983). In summary, the method is based on measuring the shift in the absorption that occurs when the pyrogallol red molybdate complex binds to the basic amino acid groups of protein molecules. Absorbance measured at $600 \mathrm{~nm}$ is directly proportional to the protein concentration in the sample. 


\section{Fermentation of chitin}

Ciliates were isolated from the rumen of monofaunated sheep (see above) and prepared as described by Bełżecki et al. (2007). In brief, the protozoa were washed with 'caudatum' solution and suspended in Hungate solution (1942), containing a new portion of antibiotics at the same concentration and composition as described above. The samples of protozoa $(40 \mathrm{ml})$ were transferred into Erlenmeyer flasks and incubated under anaerobic conditions. Three of them were incubated without chitin (control) and three were incubated with $50 \mathrm{mg}$ of chitin (experimental). The bacterial controls were obtained by filtration of the protozoa suspension through a filter with a $15 \mu \mathrm{m}$ pore diameter. The filtrate was collected and $40 \mathrm{ml}$ portions were poured into the Erlenmeyer flasks and incubated simultaneously with the cultures of ciliates in presence of the same doses of chitin. Samples for counting the protozoa and measuring the concentration of volatile fatty acids (VFA) were collected just before the start of incubation and at 3, 6, 9 and $12 \mathrm{~h}$ thereafter. The VFA concentration was measured according to Ziołecki and Kwiatkowska (1973). The protozoa count was determined as described by Michałowski et al. (1986).

\section{Statistical analysis}

Statistical analysis was processed by the Statistica 10.0 software package (StatSoft, Inc., 2011). The statistical significance of differences was calculated using one-way and two-way analysis of variance (ANOVA). Mean values were compared by Fisher's least significant difference (LSD) Test or using Student's t-test. Treatment effects were considered to be significant at $P<0.05$.

\section{Results}

\section{Effect of chitin on ciliate growth in vitro}

The results of the growth experiment are presented in Table 1. Differences between the density of $D$. affine and E. caudatum populations were found. Calculations revealed that the number of both species of protozoa was positively correlated with the amount of chitin in the $\operatorname{diet}(P<0.05)$. The increase in the population density of $D$. affine was $26 \%$ higher than that of E. caudatum.

\section{Chitin ingestion and digestion}

The ingestion of chitin by ciliates during the 24-h incubation under in vitro conditions is summarized in Table 2. The presented data revealed that only $13.3 \%$ of individuals of $D$. affine and $15.3 \%$ of E. caudatum contained food particles in the cell just
Table 1. The mean concentration of ciliates cultured in vitro on the diet without chitin (A) and diets supplemented with chitin at a ratio of: 0.015 (B), $0.03(\mathrm{C}), 0.06$ (D), $0.12(\mathrm{E}) \mathrm{mg} \cdot \mathrm{ml}^{-1}$ per day, respectively

\begin{tabular}{|c|c|c|c|c|c|c|}
\hline \multirow{2}{*}{ Protozoa } & \multicolumn{5}{|l|}{ Diet } & \multirow{2}{*}{ SE } \\
\hline & $A$ & $B$ & $C$ & $D$ & $E$ & \\
\hline $\begin{array}{l}\text { Entodinium } \\
\text { caudatum }\end{array}$ & $2023^{a}$ & $2108^{a}$ & $2162^{a b}$ & $2230^{a b}$ & $2355^{b}$ & 34.8 \\
\hline $\begin{array}{c}\text { Diploplastron } \\
\text { affine }\end{array}$ & $1504^{a}$ & $1674^{\mathrm{ab}}$ & $1851^{b c}$ & $2042^{c d}$ & $2149^{d}$ & 65.9 \\
\hline
\end{tabular}

Table 2. Changes in the proportion of protozoa with engulfed food particles ( $\%$ of total number) during 24-h incubation in control group (starved - A) and experimental group (supplemented chitin - B)

\begin{tabular}{|c|c|c|c|c|c|c|c|}
\hline \multirow{2}{*}{ Protozoa } & \multirow{2}{*}{ Group } & \multicolumn{5}{|c|}{ Incubation time, $\mathrm{h}$} & \multirow{2}{*}{ SE } \\
\hline & & 2 & 4 & 8 & 1218 & 24 & \\
\hline \multirow{2}{*}{$\begin{array}{l}\text { Diploplastron } \\
\text { affine }\end{array}$} & $A$ & $16.1^{\mathrm{a}} 16.2^{\mathrm{a}}$ & $14.8^{b}$ & $14.3^{b}$ & b $14.2^{b} 11.8^{c}$ & $9.5^{d}$ & 0.34 \\
\hline & B & $13.3^{\mathrm{a}} 38.0^{\mathrm{b}}$ & $36.0^{b}$ & b $34.7^{b}$ & ${ }^{b} 28.0^{c} 21.3^{d}$ & $17.7^{d}$ & 1.39 \\
\hline \multirow{2}{*}{$\begin{array}{l}\text { Entodinium } \\
\text { caudatum }\end{array}$} & A & $15.9^{a} 15.8^{a}$ & $15.6^{a}$ & a $12.1^{b}$ & b $11.1^{b} 11.6^{b}$ & $8.5^{c}$ & 0.41 \\
\hline & $B$ & $15.3^{a} 31.3^{b}$ & $31.1^{b}$ & $28.0^{b c}$ & ${ }^{b c} 22.7^{c} 19.7^{c d}$ & d $15.0^{\mathrm{ad}}$ & 1.00 \\
\hline
\end{tabular}

before feeding. The number of such individuals of $D$. affine and E. caudatum increased by about threeand two-fold, respectively, during the first $2 \mathrm{~h}$ after the chitin supplementation $(P<0.05)$. After this period, a continuous decrease of about $50 \%$ towards the end of incubation was observed $(P<0.05)$. In the control groups $(\mathrm{A})$, there was a continuous decrease of individuals containing food particles $(P<0.05)$.

\section{Degradation of chitin}

The degradation rate of chitin differed between the ciliate species. The crude enzyme preparation obtained from $D$. affine $\left(1.2 \mathrm{mg}\right.$ protein $\left.\cdot \mathrm{ml}^{-1}\right)$ and E. caudatum $\left(1.6 \mathrm{mg}\right.$ protein $\left.\cdot \mathrm{ml}^{-1}\right)$ digested colloidal chitin at a rate of $3.9 \pm 0.31$ and $5.9 \pm 0.76 \mu \mathrm{mol}$ $\mathrm{N}$-acetyl glucosamine $\cdot \mathrm{mg}^{-1}$ protein per $\mathrm{h}$, respectively. The optimal conditions for the degradation of colloidal chitin were $45^{\circ} \mathrm{C}$ and $\mathrm{pH} 5.0$ in the case of both species.

\section{Fermentation of chitin}

The ciliates incubated for $12 \mathrm{~h}$ with and without chitin released VFA into the medium (Figures 1 and 2). Incubation of $D$. affine and E. caudatum with chitin resulted in an increase in the VFA concentration by about $33 \%$ and $29 \%$, respectively $(P<0.05)$. The VFA content in control cultures increased by $22 \%$ and $18 \%$ and was significantly lower than in the experimental cultures $(P<0.05)$. The calculated net production rate of VFA by a single 


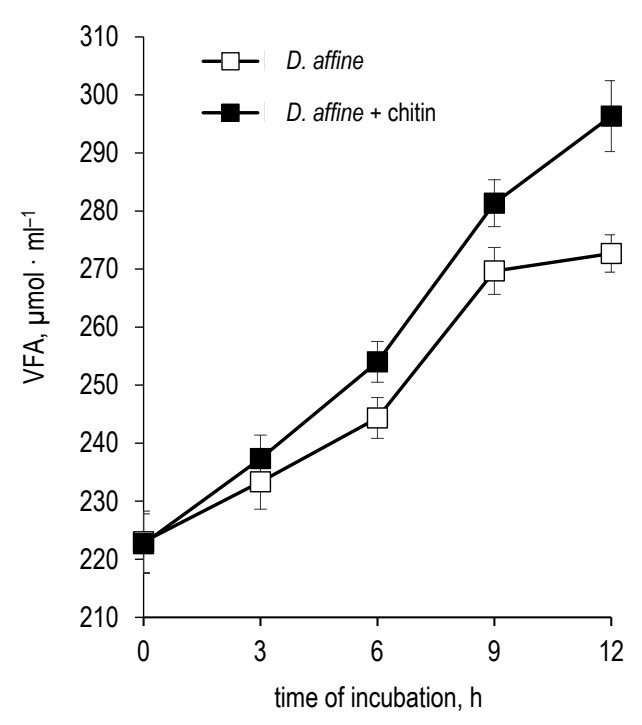

Figure 1. Changes in the concentration of volatile fatty acids (VFA) during the incubation of Diploplastron affine (D. affine) with and without chitin; mean values $(n=3)$

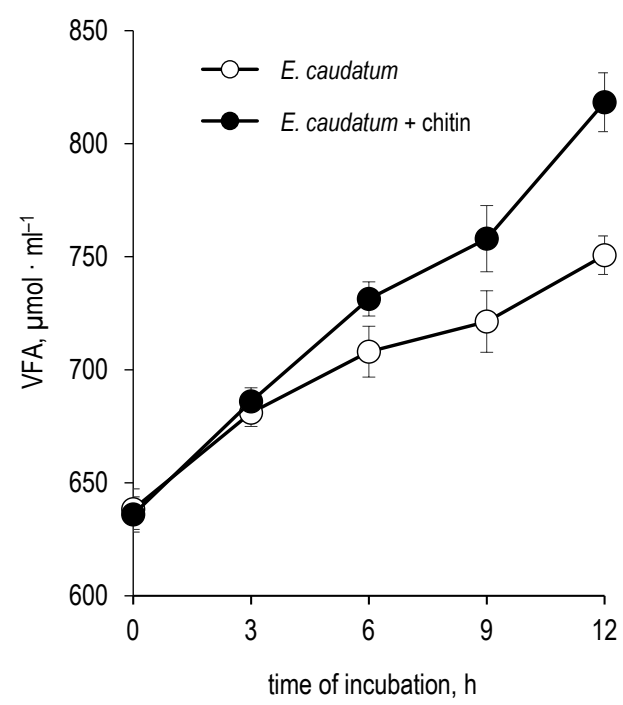

Figure 2. Changes in the concentration of volatile fatty acids (VFA) during the incubation of Entodinium caudatum ( $E$. caudatum) with and without chitin; mean values $(n=3)$

cell of $D$. affine and E. caudatum from control cultures was $3.9 \pm 0.37$ and $0.5 \pm 0.03 \mathrm{pmol} \mathrm{VFA} \cdot \mathrm{h}^{-1}$, respectively. The main products of fermentation were acetic acid (72\%) followed by butyric acid $(24 \%)$ and propionic acid (4\%), irrespective of the ciliate species. No changes were found in the concentration of VFA in the absence of protozoa (bacterial control).

\section{Discussion}

Enrichment of the culture medium with chitin increased the population of both $D$. affine and E. caudatum. A similar effect of chitin was found by Miltko et al. (2010b) in relation to E. maggii and by
Bełżecki et al. (2008), who cultivated D. affine. The positive effect of chitin was observed here despite the differences in nutrient preferences of the cultivated protozoa. It is assumed that $E$. caudatum uses starch to cover their requirement for carbohydrates (Abou Akkada and Howard, 1960). This is in contrast with D. affine, which grows well in cultures that are fed a diet devoid of starch (Michałowski et al., 1986).

The experiments on ingestion of chitin by protozoa showed an increase followed by a decrease in the number of individuals containing chitin particles. The obtained results indicate that this carbohydrate was digested inside the cell. This observation is in agreement with the data presented by Morgavi et al. (1993, 1994a,b, 1996), Bełżecki et al. (2008), and Mitlko et al. (2010a,b, 2012). The proportion of individuals engulfing chitin to the total number of protozoa was larger in the case of $D$. affine than E. cautatum. Although the length of E. caudatum is almost half that of $D$. affine, the width of the two is similar and amounts to 52 and $59 \mu \mathrm{m}$, respectively (Williams and Coleman, 1992). Comparison of the width of protozoa to the size of the chitin particles (below $10 \mu \mathrm{m}$ ) suggests that their diameter seems to be appropriate for both species and does not affect the engulfing rate. The higher uptake rate of chitin by $D$. affine may indicate that this protozoan is more chitinolytic than E. caudatum, however, the enzymatic studies do not support this suggestion. This could be because chitinolytic activity was calculated per milligram of protein in the crude enzyme preparation. The opposite effect would be obtained if this calculation were based on the number of cells from which the enzyme preparation was obtained. The optimum degradation rate of colloidal chitin for both protozoa was observed at $\mathrm{pH} 5.0$ and $45^{\circ} \mathrm{C}$. The same $\mathrm{pH}$ value was obtained by Belżecki et al. (2008), who assayed the chitinolytic activity of D. affine. However, the degradation rate of this carbohydrate found these authors was almost 55\% higher. This may have been caused by different concentrations of protein in the crude enzyme preparation, as well as the condition of the protozoa after incubation with antibiotics. Similar results of enzymatic studies were obtained by Morgavi et al. (1994b). However, it should be noted that the cited authors worked on a mixed population of protozoa and used specific substrates to determine exochitinolytic activity. The colloidal chitin used in the present study permitted determination of total chitinolytic activity (sum of endo- and exochitinolytic activities). Accordingly, it could be expected that the obtained values would be higher than presented by Morgavi et al. (1994a). The reasons for this could be: different methods of crude enzyme preparation, lower 
concentration of protein and the sensitivity of measurements.

The results of fermentation studies also confirmed that $D$. affine is more chitinolytic than E. caudatum. It was calculated that the net production rate of VFA by the small protozoan, E. caudatum, was almost 8 times lower in comparison with the larger $D$. affine when this parameter was expressed per ciliate cell. The main products of chitin fermentation were acetate, followed by butyrate and propionate. Similar proportions between the particular acids were found when cellulose (Michałowski et al., 1997), murein (Bełżecki et al., 2010) and chitin (Miltko et al., 2010b) were fermented by various species of rumen protozoa.

\section{Conclusion}

The obtained results confirm that Diploplastron affine can digest and utilize chitin and show that Entodinium caudatum also possesses this ability; their comparison indicates that Diploplastron affine is the more chitinolytic species.

\section{References}

Abou Akkada A.R., Howard B.H., 1960. The biochemistry of rumen protozoa. 3. The carbohydrate metabolism of Entodinium. Biochem. J. 76, 445-451

Bełżecki G., Miltko R., Kwiatkowska E., Michałowski T., 2010. Mureinolytic ability of the rumen ciliate Diploplastron affine. Folia Microbiol. Prague 55, 312-314

Bełżecki G., Miltko R., Michałowski T., Simůnek J., Kopecný J., 2008. Chitinolytic activity of the sheep rumen ciliate Diploplastron affine. Folia Microbiol. Prague 53, 201-203

Bełżecki G., Newbold C.J., McEwan N.R., Mclntosh F.M., Michałowski T., 2007. Characterization of the amylolytic properties of the rumen ciliate protozoan Eudiplodinium maggii. J. Anim. Feed Sci. 16, 590-606

Coleman G.S., Davies J.I., Cash M.A., 1972. The cultivation of rumen ciliates Epidinium ecaudatum caudatum and Polyplastron multivesiculatum in vitro. J. Gen. Microbiol. 73, 509-521

Dogiel V.A., 1927. Monographie der Familie Ophryoscolecidae. Arch Protistenk. 59, 1-288

Doré J., Mackie R.I., 1997. Microbial diversity in gut ecosystem. Reprod. Nutr. Develop. 37, 15-20

Fujita Y., Mori I., Kitano S., 1983. Color reaction between pyrogallol red-molybdenum (VI) complex and protein. Bunseki Kagaku 32, E379-E386
Hungate R.E., 1942. The culture of Eudiplodinium neglectum, with experiments on the digestion of cellulose. Biol. Bull. 83, 303-319

Lee S.S., Ha J.K., Cheng K.J., 2001. The effects of sequential inoculation of mixed rumen protozoa on the degradation of orchard grass cell walls by anaerobic fungus Anaeromyces mucronatus 543. Can. J. Microbiol. 47, 754-760

Michałowski T., 1997. Digestion and fermentation of the microcrystalline cellulose by the rumen ciliate protozoon Eudiplodinium maggii. Acta Protozool. 36, 181-185

Michałowski T., Harmeyer J., Bełżecki G., 1999. The importance of washing the omasum for successful defaunation of sheep. J. Anim. Feed Sci. 8, 611-619

Michałowski T., Szczepkowski P., Muszyński P., 1986. The nutritive factors affecting the growth of the rumen ciliate Diploplastron affine in vitro. Acta Protozool. 25, 419-426

Miller G.L., Blum R., Glennon W.E., Burton A.L., 1960. Measurement of carboxymethylcellulase activity. Anal. Biochem. 1, 127-132

Miltko R., Bełżecki G., Kasperowicz A., Michałowski T., 2010a. Isolation and purification of chitinolytic enzymes of rumen ciliates Eudiplodinium maggii. PCACD 15, 189-196

Miltko R., Bełżecki G., Kowalik B., Michałowski T., 2014. Can fungal zoospores be the source of energy for the rumen protozoa Eudiplodinium maggii? Anaerobe 29, 68-72

Miltko R., Bełżecki G., Kwiatkowska E., Michałowski T., 2010b. The ability of the rumen protozoan Eudiplodinium maggii to utilize chitin. Folia Microbiol. Prague 55, 349-351

Miltko R., Bełżecki G., Michałowski T., 2012. Chitinolytic enzymes of the rumen ciliate Eudiplodinium maggii. Folia Microbiol. Prague 57, 317-319

Morgavi D.P., Onodera R., Nagasawa T., 1993. In vitro metabolism of chitin and protein from ruminal fungi by ruminal protozoa. Anim. Sci. Tech. (Jpn.) 64, 584-592

Morgavi D.P, Sakurada M., Mizokami M., Tomita Y., Onodera R., 1994a. Effects of ruminal protozoa on cellulose degradation and the growth of an anaerobic ruminal fungus, Piromyces sp. strain OTS1, in vitro. Appl. Environ. Microbiol. 60, 3718-3723

Morgavi D.P., Sakurada M., Tomita Y., Onodera R., 1994b. Presence in rumen bacterial and protozoal populations of enzymes capable of degrading fungal cell walls. Microbiology 140, 631-636

Morgavi D.P., Sakurada M., Tomita Y., Onodera R., 1996. Electrophoretic forms of chitinolytic and lysozyme activities in ruminal protozoa. Curr. Microbiol. 32, 115-118

Shimahara K., Takiguchi Y., 1988. Preparation of crustacean chitin. Methods Enzymol. 161, 417-423

StatSoft, Inc., 2011. STATISTICA (data analysis software system). version 10. www.statsoft.com

Williams A.G., Coleman G.S. (Editors), 1992. The Rumen Protozoa. Brock/Springer Series in Contemporary Bioscience. SpringerVerlag, New York (USA)

Ziołecki A., Kwiatkowska E., 1973. Gas chromatography of C1 to $\mathrm{C} 5$ fatty acids in rumen fluid and fermentation media. J. Chromatogr. 80, 250-254 